\title{
UTILIZATION OF RECYCLED POLYPROPYLENE, CELLULOSE AND NEWSPRINT FIBRES FOR PRODUCTION OF GREEN COMPOSITES
}

\author{
Vesna Ž. Bogataj ${ }^{1, *}$, Peter Fajs ${ }^{1}$, Carolina Peñalva ${ }^{2}$, Marko Omahen ${ }^{3}$, Matjaž Čop ${ }^{4}$ and \\ Ari Henttonen ${ }^{5}$
}

${ }_{1}^{1}$ TECOS, Slovenian Tool and Die Development Centre, Kidričeva 25, 3000, Celje, Slovenia

${ }^{2}$ AITIIP Centro Tecnológico, Romero 12, 50720, Zaragoza, Spain

${ }^{3}$ OMAPLAST, Kosovelova cesta 3, 1230, Grosuplje, Slovenia

${ }^{4}$ ADRIA Mobil, Straška cesta 50, 8000, Novo Mesto, Slovenia

${ }^{5}$ ECOPULP Finland Oy, Suviojantie 9, 45610, Koria, Finland
Article Info:
Received:
01 July 2019
Revised:
18 September 2019
Accepted:
20 September 2019
Available online:
26 September 2019
Keywords:
Waste plastics
Recycled polypropylene
Newspaper fibre
Reclaimed cellulose fibre
Mechanical properties
Thermal properties
Fibre reinforced composites
Recycling

\begin{abstract}
This work investigates the feasibility of using the recycled polypropylene (rPP), cellulose (CF) and newsprint (NP) fibres in polyolefin reinforced composites. Recycled PP filled with 40 wt.\% of cellulose (rPP/CF) or newsprint (rPP/NP), with the addition of impact modifier (IM) and compatibilizing agent (CA), have been prepared with extrusion melting and injection moulding. Melting and crystallization behaviour of plain matrix and composites were measured by differential scanning calorimetry (DSC). Morphological and mechanical properties were also studied using scanning electron microscope (SEM) and tensile testing, respectively. Thermal stability of composites was similar to neat rPP for both types of the filler used. Though, the crystallinity was progressively decreased with the addition of CF or NP. The DSC further revealed an occurrence of the two distinct melting transitions, meaning that the examined materials were not based on pure polypropylene (PP), but are rather blends of high-density polyethylene (HDPE) and PP, what has been confirmed also by the Fourier transform infrared spectroscopy (FTIR). The largest single source of contaminations in recycled PP comes from HDPE since both polymers are identified by a similar density and can be accidentally mixed during the conventional physical separation process. Composites reinforced with CF have shown better mechanical performances than those based on reclaimed NP fibres, what can be attributed to the initial fibre quality. Tensile strength of the composites filled with CF and NP fibres was $36 \mathrm{MPa}$ and 29 $\mathrm{MPa}$, respectively, in disparity to $23 \mathrm{MPa}$ measured for neat rPP. The fibre addition further resulted in substantial increase in Young modulus of the composites. The addition of CF and NP fibres lead to an improved modulus of elasticity by 16 and $47 \%$, respectively. Waste paper in the form of recovered cellulose or reclaimed newsprint fibre can thus meet all the technical requirements to become an alternative to inorganic fillers in thermoplastic composites.
\end{abstract}

\section{INTRODUCTION}

One of the key priorities of the EU Strategy for Circular Economy is an accelerated shift to a more resource efficient economic model in Europe, providing a pragmatic and effective solution to the gradual and limited depletion of virgin resources. By closing the material cycles in production sectors, this modern economy allows Europe to increase the resource productivity by up to 3 percent annually. This would generate a primary resource benefit of as much as 0.6 trillion EURO per year by 2030 (EMF and McKinsey, 2015) to the Europe's economies. In addition to the ecological and economical awareness, the legisla- tive actions adopted along the EU member states likewise strongly encourage the development of reusability and recycling modelling for discarded materials, including waste paper and plastics.

Paper is the most recycled product in the world and Europe is the global champion in paper recycling, exceeding the rate of $72 \%$ (EPRC, 2017). On the other hand, scarcely around $26 \%$ of all plastics streams are recycled in Europe (Shen and Worrell, 2014). In 2016, 27.1 million tonnes of plastic waste were collected through official schemes in the $\mathrm{EU} 28+\mathrm{NO} / \mathrm{CH}$ in order to be reintegrated back into the production cycles. Out of this volume, $31.1 \%$ of plastic waste was recycled, $41.6 \%$ was incinerated, and $27.3 \%$ has been 
committed to the landfills. This year represents an important milestone, since for the first time, more plastic waste was recycled than landfilled (PlasticsEurope, 2018). In addition, the recent Chinese "Green Fence" policy has limited the export of waste plastics to China and this has caused a build-up of waste materials in Europe. The implications of Europe's substantial exports of plastics waste are now becoming clearer as the issues arise from the Green Fence blockade. Europe now needs to find a resolution in order to allow new investments in plastic waste recycling and to deal with the plastic waste that was in past exported. The challenge to recycle more and to fully implement the waste hierarchy model, with prevention, reuse, recycling, recovery and disposal as the least preferable option, continues and remains as one of the most important shift tags in implementation of the EU Circular Economy Package (EC, 2015). There are many product types that are currently not widely collected but could be in future. For example, advanced sorting technologies for PP are now available but not yet fully implemented as an operative collection system is not yet in place.

The possibility of using the municipal solid wastes in the development of new value-added products is an attractive venture, especially with respect to the large quantity of paper and plastic waste generated daily. The throwaway era is behind us, and these days we need to focus on endof-service life and recycling issues for these materials. Since the composites are naturally mixtures of different materials, it is reasonable to expect that it would be easier and less expensive to utilize the mixed waste plastics in them.

If we look further, the recycled paper fibre can meet all the requirements for replacing the inorganic fillers in thermoplastic composites, what has been thoroughly reviewed in the literature (Mochane et al. 2019; Jariwala and Jain, 2019). Although waste paper recycling maintains an important role in a sustainable environment, the use of recycled/secondary fibre for making the paper requires special treatments for deinking, cleaning and refinement. Subsequent wastewater and sludge treatments significantly increase the production costs. On the contrary, the utilization of recycled and recovered paper fibres as reinforcers in a composite does not require extensive pre-treatments, but decreases the demand for natural resources, saves energy and water, and reduces pollution. The added advantage of these composites results from maintaining trees by reducing the use of virgin natural fibres, making the products cheaper on a price per weight basis, since fillers are often less expensive than the polymer, while at the same time increasing their end performances. A continuous upgrade of such materials in terms of mechanical, thermal and dimensional performances has demonstrated the industrial applicability to various fields of applications, specifically for load-bearing applications. Thanks to their genuine technical, cost-efficient and environmental advantages, natural fibre reinforced composites (Sydow \& Bieńczak, 2018; Holbery \& Houston, 2006; Kowaluk, 2017) are flourishing and can no longer be considered merely as an example of "greenwashing".

The ultimate goal of this research is to study the proper- ties of the produced composites, prepared for maximised fractional utilisation of the waste paper fillers, balanced against the deleterious effects on the material properties, while remaining potentially an economically viable process. All the input materials for new composites were derived from municipal solid waste, i.e. recovered newsprint fibres, reclaimed cellulose fibres, and recycled waste plastic polyolefines (rPP). The effects of various filler types, impact modifier and compatibilizing agent on the mechanical and thermal properties of the resulting composites were evaluated and compared with the properties of plain rPP.

This study is a part of the LIFE CEPLAFIB project (LIFE17 ENV/SI/000119) in which eco-composites based on recycled polyolefines reinforced with different natural fibres and fillers, obtained as byproducts from industrial production plants, are being developed and investigated for its industrial use as a sandwich acoustic barrier panels in construction/building sector, rigid packaging insertions for industrial packaging and interior RV equipment for the caravanning sector.

\section{EXPERIMENTAL}

\subsection{Materials}

Recycled polypropylene (rPP) was supplied by the recycling company OMAPLAST (Slovenia) with a melt flow index (MFI) between 7.0 and $10.0 \mathrm{~g} / 10 \mathrm{~min}$, and the density of $0.910 \mathrm{~g} / \mathrm{cm}^{3}$. Virgin PP (BormedTM RF830-MO), supplied by Borealis (Vienna, Austria) and virgin HDPE (HDI2061 Natural), supplied by Braskem IDESA, Mexico), were used in FTIR comparative analysis, serving as the reference spectra. Cellulose (CF) and newsprint (NP) fibres were provided by Ecopulp Oy (Koria, Finland) after chemical bleaching and mechanical recovering, respectively, of the received waste residues from pulp \& paper industry. NP and CF were shredded into smaller fraction particulates and dried in a vacuum oven at $60^{\circ} \mathrm{C}$ over-night to ensure that the moisture content was minimal. The measured aspect ratio (defined as the ratio of fibre length to diameter) was 38 for NP and 58 for CF. The percentage of fibre additivation was in all cases 40 wt. \%. Liococene PP-MA 7452 TP (CA), grafted with 7 wt.\% of maleic anhydride, supplied from Clariant Produkte (Deutschland) $\mathrm{GmbH}$, Germany, was used as compatibilizer, and propylene-based elastomer Vistamaxx ${ }^{\mathrm{TM}}$ 6202, supplied by HSH Chemie Group, Slovenia, served as an impact modifier (IM). The blend composition and sample designations used in this study are presented in Table 1. The composition of the composite materials has been selected on the basis of the preliminary results obtained, where 26 different formulations has been studied and tested, varying the type of fillers (i.e. newsprint fibres with two different size reductions: NP sieved to final fraction of $2 \mathrm{~mm}$ and milled NP fibres, cellulose fibres and barely husk fibres), filler contents (0,20, 30 and 40 wt. \%) and the contents of $\mathrm{CA}(0,3$ and $5 \mathrm{wt}$. \%) and IM (0, 3 and 5 wt. \%) in the final formulation.

\subsection{Processing}

All the raw components were premixed in sealed containers and shaken manually. The blends were com- 
pounded by simultaneous addition of all components into the Labtech LTE 20-44 twin screw extruder with a barrel temperature of $170^{\circ} \mathrm{C}$ at the feed section and $180^{\circ} \mathrm{C}$ at the die head. The screw rotation speed was fixed at 200 rpm. The extruded strands were quenched in water and pelletized. The extruded blends were injection moulded into standard tensile specimens. Prior to injection moulding, pellets were dried in a dryer $\left(60^{\circ} \mathrm{C}\right.$ for 24 hours). A Krauss Maffei 80/380 CX injection moulding machine was used with barrel temperatures of $150-180^{\circ} \mathrm{C}$. The injection-moulded specimens were then stored in desiccators prior to testing.

\subsection{Characterization Analyses}

\subsubsection{Tensile Testing}

Tensile tests using a Zwick/Roell Z005 (Zwick GmbH \& Co. KG, Ulm, Germany) were carried out in compliance with ISO 527-1-2 under the ambient conditions with a crosshead speed of $5 \mathrm{~mm} \mathrm{~min}{ }^{-1}$. The distance between the grips was set to $60 \mathrm{~mm}$. The presented values of elasticity modulus $\left(E_{t}\right)$, tensile strength $\left(\sigma_{M}\right)$, and elongation at break $\left(\varepsilon_{b}\right)$ are an average from at least six replicates from each final material.

\subsubsection{Differential Scanning Calorimetry}

The melting and crystallization behavior of neat rPP and composites were studied using a Mettler-Toledo HP DSC-1 with a temperature range of $25-180^{\circ} \mathrm{C}$, under the nitrogen purge and heating rate of $10^{\circ} \mathrm{C} / \mathrm{min}$. Crystallization temperature $(\mathrm{Tc})$, melting temperature $(\mathrm{Tm})$, enthalpy of crystallization $(\Delta \mathrm{Hc})$, and enthalpy of melting $(\Delta \mathrm{Hm})$ of samples were calculated. The percent of crystallinity (\% $\mathrm{Xc}$ ) was calculated from the Equation (1), where is the fusion heat of $100 \%$ crystalline PP (equal to $207 \mathrm{~J} \mathrm{~g}^{-1}$; TA Instruments) or (HD)PE (equal to $293 \mathrm{~J} \mathrm{~g}^{-1}$; Wunderlich, 1990) and $\mathrm{Wv}$ represents the mass fraction of the polymer component within the final composites formulation.

$\mathrm{Xc}(\%)=\frac{\Delta H_{m}}{W_{v} \cdot \Delta H_{m}^{0}} \times 100$

\subsubsection{Fourier-transform infrared spectroscopy}

The chemical structure of recycled PP was analysed with Fourier transform infrared spectroscopy. For the identification of recyclate composition, the spectra of virgin PP and HDPE were also recorded to enable the comparative analysis based on their specific absorption bands. All the samples were prepared in the form of thin films. The instrument used was a Spectrum One FTIR spectrometer (Perkin Elmer, USA), working in the attenuated total reflection (ATR) mode on a ZnSe crystal. The spectra were collected at a resolution of $4 \mathrm{~cm}^{-1}$ over the range from 650 to 4000 $\mathrm{cm}^{-1}$. In total, 64 scans were averaged for each spectrum.

\subsubsection{Scanning Electron Microscopy}

Morphology of the composite fractured surfaces were examinated after tensile test using low vacuum JEOL 5500 LV scanning electron microscope (SEM), equipped with Oxford Inca (EDX) energy dispersive spectroscopy. An operating voltage of $20 \mathrm{kV}$ and magnifications of 100x and 500x were used.

\section{RESULTS AND DISCUSSION}

\subsection{Mechanical properties}

Results of the tensile modulus $\left(E_{t}\right)$, tensile strength $\left(\sigma_{M}\right)$ and elongation at break $\left(\varepsilon_{\mathrm{b}}\right)$ of plain rPP and composites with two different reinforcing components, i.e. CF and NP, as a function of CA and IM additivation are presented in Table 2. The representative stress-strain curves are illustrated in Figure 1. In general, the addition of the reinforcing elements, independly of their origin (CF or NP), has proven to be a successful technique for improving the mechanical properties of the basic polymer matrix. The values of the tensile modulus and strength obtained for the resulting composites were substantially higher than that of plain recycled PP. Compared to the neat rPP the addition of CF or NP fibres lead to an improved modulus of elasticity by $16 \%$ and $47 \%$, respectively, and the values of the tensile strength for samples filled with CF and NP fibres was $36 \mathrm{MPa}$ and $29 \mathrm{MPa}$, respectively, in contrast to the $23 \mathrm{MPa}$ measured for recycled neat PP. The elongation at break on the other hand was decreased with the addition of fibres. This is governed by the fact that composites become more brittle with the addition of flaky fillers, however higher strength means a harder thus less deformable material. Since polypropylene has a hydrophobic nature and the cellulose based fibres has a hydrophilic surface charge, the usage of maleic anhydride grafted coupling agent has certainly contributed

TABLE 1: Sample composition of rPP/CF and rPP/NP Composite.

\begin{tabular}{l|ccccc:c}
$\begin{array}{l}\text { Sample } \\
\text { formulation }\end{array}$ & $\begin{array}{c}\text { rPP } \\
\text { [wt. \%] }\end{array}$ & $\begin{array}{c}\text { CF } \\
\text { [wt. \%] }\end{array}$ & $\begin{array}{c}\text { NP } \\
\text { [wt. \%] }\end{array}$ & $\begin{array}{c}\text { CA } \\
\text { [wt. \%] }\end{array}$ & $\begin{array}{c}\text { IM } \\
\text { [wt. \%] }\end{array}$ \\
\hline rPP & 100 & 0 & 0 & 0 & 0 \\
\hdashline rPP/CF & 52 & 40 & 0 & 3 & 5 \\
\hdashline rPP/NP & 52 & 0 & 40 & 3 & 5 \\
\hline
\end{tabular}

TABLE 2: Mechanical properties of rPP and composites with respect to the type of the reinforcing filler.

\begin{tabular}{l|c:c:c} 
Sample & $\begin{array}{c}\text { Young Modulus } \\
\mathbf{E}_{\mathrm{t}} \text { [MPa] }\end{array}$ & $\begin{array}{c}\text { Tensile Strength } \\
\sigma_{\mathrm{T}} \text { [MPa] }\end{array}$ & $\begin{array}{c}\text { Elongation at } \\
\text { Break } \boldsymbol{\varepsilon}_{\mathrm{b}} \text { [\%] }\end{array}$ \\
\hline $\mathrm{rPP}$ & $384 \pm 18$ & $23 \pm 0.05$ & $49 \pm 6.00$ \\
\hdashline $\mathrm{rPP} / \mathrm{CF}$ & $447 \pm 14$ & $36 \pm 0.44$ & $11 \pm 0.22$ \\
\hdashline $\mathrm{rPP} / \mathrm{NP}$ & $564 \pm 68$ & $29 \pm 0.46$ & $09 \pm 1.96$ \\
\hline
\end{tabular}

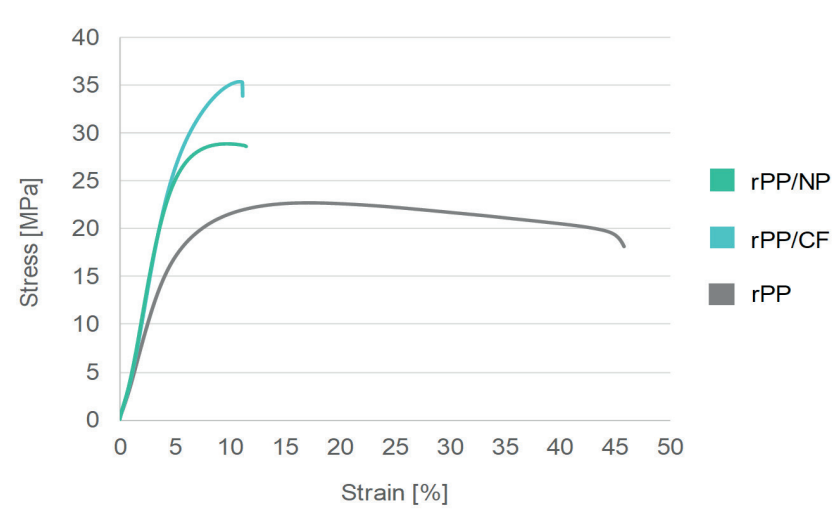

FIGURE 1: Comparison of tensile stress versus strain curve for rPP and composites filled with CF and NP fibres. 
to the amplified inter-phase compatibility, as evidenced also by the SEM results, and hence the adhesion between the components of the composite (Yang et al. 2007; Žepič et al. 2016).

In addition to the tolerable interphase compatibility, various supplementary parameters are also influencing the mechanical performances of fibre reinforced composites, including the fibre aspect ratio, filler dispersion, particle dimension, stress transfer at the interface and mixing temperatures (Ashori and Nourbakhsh, 2008). To achieve a proper trade off between the elasticity and stiffness of the resulting composites, Vistamaxx ${ }^{\mathrm{TM}}$ propylene-based elastomer has been added to the mixture blends in a relative high weight percentatge which appears to deliver good impact properties (Kumar et al. 2017), but still moderate flexibility.

\subsection{Thermal properties}

The impact of the type of fibre additivation on the thermal characteristics of rPP compounds can be assessed from the results obtained from DSC thermographs that are graphically presented in Figure 2. The crystalization $\left(X_{c}\right)$ and melting $\left(T_{m}\right)$ behaviour was evaluated from the $2^{\text {nd }}$ heating scan, while the crystallization temperature (CT) of the neat recycled polymer and composites was studied from the cooling scan. The results are shown in Table 3.

The thermal stability of the composites with recycled PP and recovered cellulose/newsprint fillers were similar to those of neat rPP. However, the enthalpy of fusion for the composites progressively decreased with the addition of cellulose and newsprint fibres, which can be attributed to the lower content of the polymer in final material composition. In fact, cellulose-based fibres does not essentially contribute to the melting endotherm, since this type of fillers does not present any transitions within the temperature range of DSC scan. Furthermore, if the obtained values of the melting enthalpies are normalized on the basis of pure polymer content of each sample, still a modest decrease enthalpy with the fibre content can be observed for most cases. This effect suggests that some interactions between cellulose/newsprint fibres and polyolefin matrix take place. The degree of crystallinity, calculated using the Eq. 1, is higher for the composite than for the neat rPP (Table 3). This behaviour indicates that newsprint or cellulose fibres can induce crystal nucleation of the recycled polymer matrix, which implies that both of the utilized fillers can probably be used as a nucleating agent for rPP. Similar observations were made by other authors (Lopez-Machado
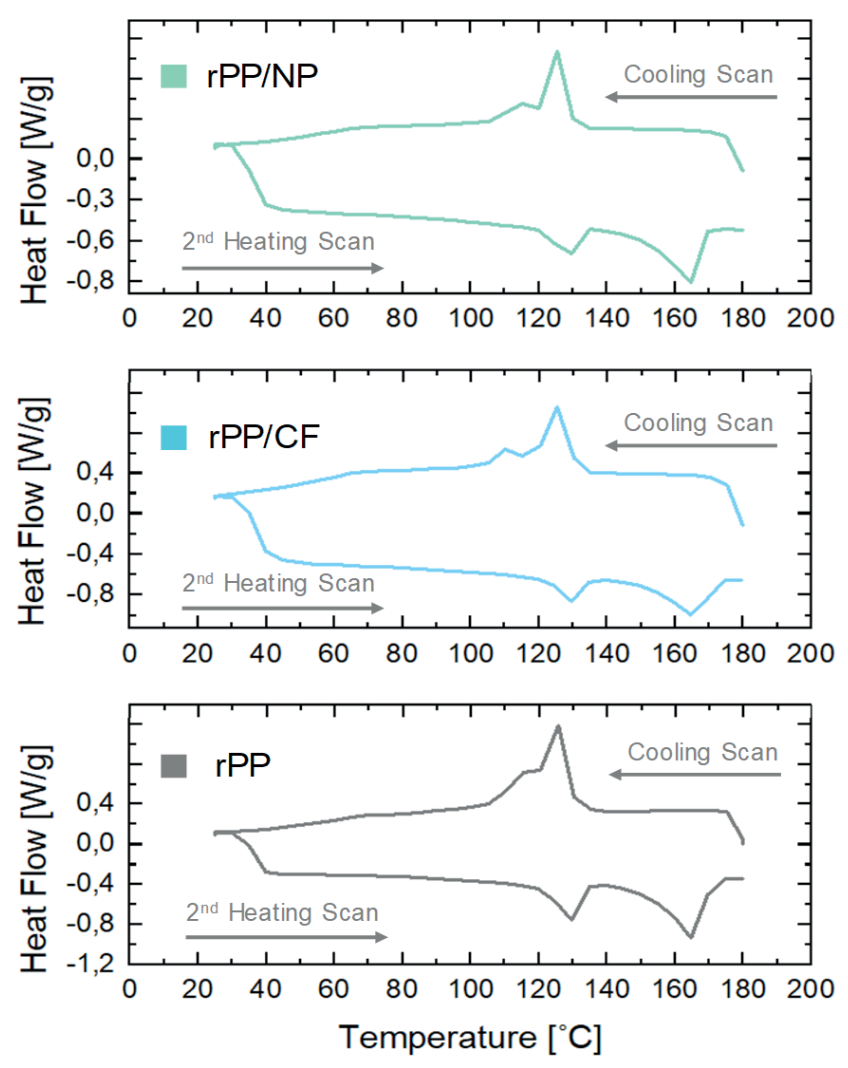

FIGURE 2: DSC thermograms of rPP and composites with reclaimed CF and NP fibres during the cooling and the second heating scan.

et al. 2000). By comparsion between the two types of composites, a slightly higher crystallinity yield is observed for the $\mathrm{rPP} / \mathrm{CF}$ composites as compared to the rPP/NP. The stronger adhesion between the rPP matrix and the NP fibres, as imposed by the surface morphology features of the composites, could hinder the motion of the polymer chains which are close to the NPs. This decrease in mobility could be an explanation of the lower crystalline ratio.

What was more interesting is that the DSC results revealed the occurrence of the two distinct melting transitions, implicating that the examined materials are not based on pure PP, but are rather blends of HDPE (peak melting temperature at around $130^{\circ} \mathrm{C}$ ) and PP (melting of about $165^{\circ} \mathrm{C}$ ) (Camacho and Karlsson, 2001). Pure or homogeneous PP resin should yield a single melting event and the presence of the smaller endothermic transition, evolved at lower melting temperatures $\left(130^{\circ} \mathrm{C}\right)$, indicates

TABLE 3: DSC data of neat rPP and composites with respect to different fillers during the first and second heating scan.

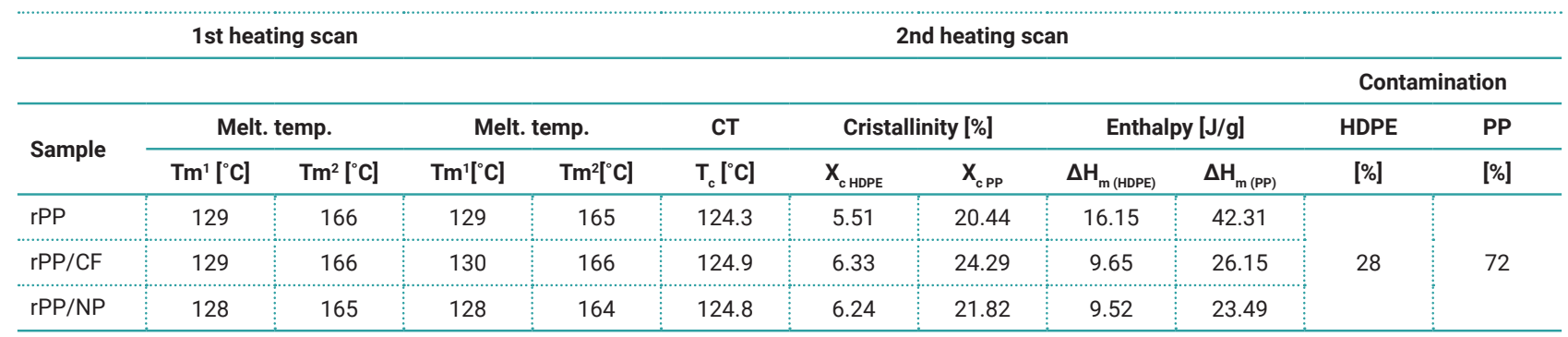


the presence of HDPE, which could be accidentally mixed with the PP recycled containers or resins. A substantial part of public solid waste (MSW) streams is composed of mixed polymers, like polyethylene (PE), polypropylene (PP), polyvinyl chloride (PVC) and polyethylene terephthalate (PET), which are among the most common plastics waste, since they are the most frequently used commercial plastics in our daily lives as well as in industries. PP and HDPE have similar densities and by using the conventional physical separation technique (i.e. floating drop process) is almost impossible to separate them. The misclassification of these two types of plastic waste is highly probable in the daily waste sorting routine and explains the reason for the presence of HDPE in the PP matrix.

According to the application guide of the original equipment manufacturer of DSC measuring devices, the DSC heats of melting do not only detect the contaminant, but can also determine its percent level in the final resin (Sichina, 2000). To make a rapid qualitative assessment of the polyolefin blend composition we need to divide the measured melting enthalpy of the "contaminant" $\left(\Delta \mathrm{H}_{\mathrm{m} \text { HDPE }}\right)$ with the total $\Delta \mathrm{Hm}$ of the rPP recyclate. The estimated percent level of the HDPE in the final material composition was, according to this calculation, equal to $30 \%$.

\subsection{Chemical Composition}

The ATR-FTIR spectroscopy analysis was elaborated as a qualitative (aiding polymers identification based on their specific absorption bands) method for assessing the chemical composition of the recyclate PP. The representative FTIR spectra of virgin PP and HDPE, and the spectra of recycled $P P$ are presented in Figure 3. In order to differentiate between the HDPE and PP the $3000-2750 \mathrm{~cm}^{-1}$ spectral region has been firstly taken into consideration. This frequency range is related to different vibration types of methyl groups, wherein the absorption bands between 2950 and $2850 \mathrm{~cm}^{-1}$ represents the - $\mathrm{CH} 2-$ asymmetric and symmetric stretching vibration that typically belongs to HDPE,

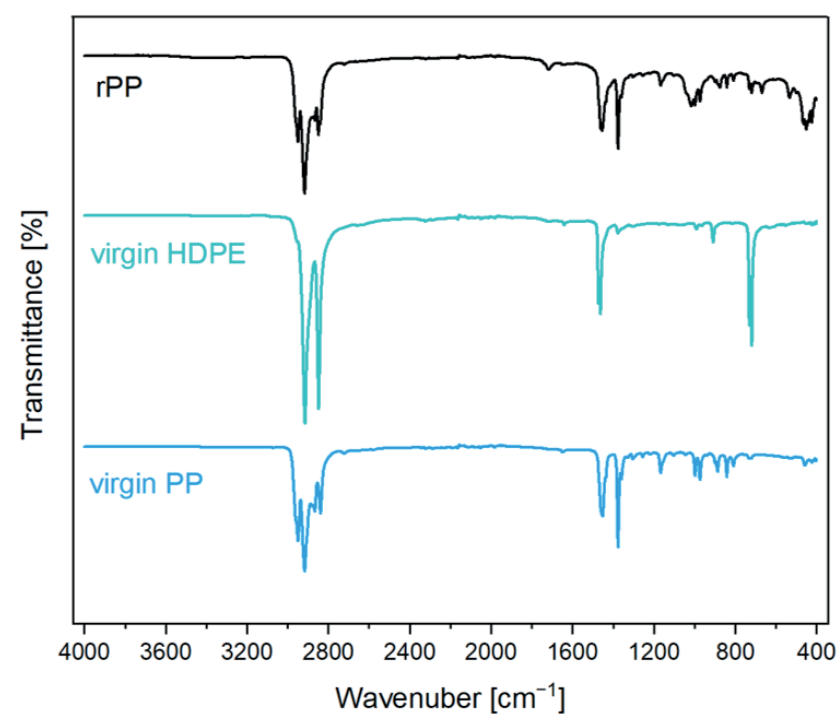

FIGURE 3: FTIR spectral comparison of rPP, virgin high-density polyethylene and virgin polypropylene. while four superimposed absorption bands in between $2985 \mathrm{~cm}^{-1}$ and $2810 \mathrm{~cm}^{-1}$ correspond to the asymmetric and symmetric stretching vibration of methylene and methyl groups, and are subscribed to PP (Lin et al. 2015). Variations between the spectra were also observed in the 1475$1350 \mathrm{~cm}^{-1}$ domain, where absorption bands correspond to scissoring vibration of the methylene group (1470-1460 in HDPE, and $1475-1440 \mathrm{~cm}^{-1}$ in PP spectrum) and to symmetric deformation of the methyl group (1380-1370 $\mathrm{cm}^{-1}$ only in PP spectrum). Supplementary, a doublet with the maxima at 730 and $720 \mathrm{~cm}^{-1}$, corresponds to bending and rocking vibrations of crystalline and amorphous methylene group, is characteristically assigned to HDPE. The frequency ranges of different functional groups of PP and HDPE polymers, with assigned vibration type are summarized in Table 4.

By comparing the rPP spectrum to the reference spectra of virgin PP and HDPE it can be argued that the main chemical structure of the recyclate belongs to PP and, in lower amount to high density polyethylene (HDPE). On the other hand, all the characteristics peaks of PP and HDPE can be found also in rPP spectrum, confirming the co-existence of both polymer types as formerly speculated by the results of DSC analysis.

\subsection{Morphology Analysis}

The interface in any fibre-matrix composite system is responsible for transmitting the load stresses from the polymer to the fibres. This stress transfer efficiency largely depends on the fibre-matrix interface and fibres quality, i.e. morphology and mechanical characteristics (Kalia et al. 2011).

SEM images of recovered bleached cellulose fibres and recycled newsprint fibres were taken to investigate their surface structure and are shown in Figure $4 a$ and $4 b$, respectively. The results illustrated smooth and clean surface of bleached cellulose fibres, while the mechanically reclaimed newsprint fibres indicated rougher surface texture, signifying the presence of impurities such as hemicellulose, lignin, pectin and waxy substances. Furthermore, the average diameters of the measurable newsprint fibres (36 $\pm 10 \mu \mathrm{m}$ ) were higher than those of chemically bleached cellulose fibres $(30 \pm 12 \mu \mathrm{m})$. This can be explained by the fact that bundles of individual newsprint fibres are linked together with lignin, which acts like a cementing material around the fibre strands.

The original pulping process for newsprint fibres is high yield mechanical pulping, consequently, the external

TABLE 4: FTIR spectra analysis of PP and HDPE polymers.

\begin{tabular}{l|c|c|c}
$\begin{array}{l}\text { Wave number } \\
\left(\mathbf{c m}^{-1}\right)\end{array}$ & $\begin{array}{c}\text { Functional } \\
\text { group }\end{array}$ & $\begin{array}{c}\text { Vibration } \\
\text { type }\end{array}$ & $\begin{array}{c}\text { Assigned } \\
\text { to }\end{array}$ \\
\hline $2985-2810$ & $-\mathrm{C}-\mathrm{H}$ & Streching & $\mathrm{PP}$ \\
\hline $2950-2850$ & $-\mathrm{CH}_{2}$ & Streching & HDPE \\
\hline $1475-1440$ & $-\mathrm{CH}_{2}$ & Bending & $\mathrm{PP}$ \\
\hline $1470-1460$ & $-\mathrm{CH}_{2}$ & Bending & HDPE \\
\hdashline $1380-1370$ & $-\mathrm{CH}_{3}$ & Bending & PP \\
\hline $730-700$ & $-\mathrm{CH}_{2}$ & Rocking & HDPE \\
\hline
\end{tabular}


surface of fibres tends to be rich in lignin, hence to some extent hydrophobic (Gregersen et al. 1995; Backström et al. 1999), and with lower strength properties (Kibblewhite, 1983). By contrast, the removal of lignin and extractives during the chemical bleaching will result in a hydrophilic fibre surface due to carbohydrates (cellulose, hemicelluloses) and better strength compared to newsprint fibre. The aim of the present study was, inter alia, to compare the effect of mechanically recycled newsprint fibres and bleached cellulose fibres on the ultimate mechanical properties of the resulting composites. The quality of the fibres for their reinforcement potential, including the developed surface characteristics (Figure 4), is therefore closely related to the fibre pre-treating process.

Figure 5 shows a comparison of the effect of filling the recycled polypropylene matrix with $40 \%$ of reclaimed cellulose and newsprint fibres. We can observe the difference between the morphology of the composites, depending of the chosen natural fibres - longer cellulose fibres seem to be more coherent and break perpendicularly to the polymer matrix (Figure 5a, b), while newsprint fibres are firmly embedded within the polymer matrix (Figure $5 c$, d) suggesting a strong interfacial adhesive bond. On the fractured surfaces of the composites, we can observe that some fibres are pulled out from the matrix, but most of them are still tightly linked to the matrix. This last statement is factual for both types of composites and can be attributed to the compatibilizing agent effect. The results of thermal and mechanical analysis indicated higher cristallinity and improved tensile strength for cellulose-reinforced composites as opposed to recycled newsprint fibre composites, therefore, the assumption that chemically bleached fibres express a higher reinforcing potential can be clearly confirmed.

\section{CONCLUSIONS}

The present study has shown that composites based on recycled polypropylene filled with natural reclaimed fibres obtained from post-consumer waste, can be an interesting alternative to virgin polymer materials modified by artificial fibres like glass or aramid. This leap to natural fibre reinforcements reduces the mechanical properties of the composites, when compared to glass or aramid fibres.
Nevertheless, the resulting materials show good specific properties due to the lower density of the natural cellulose-based fibres. Moreover, these fibres are more flexible and less abrasive than glass fibres, protecting the machinery and allowing higher recyclability rates. In the case of adding the recovered newsprint fibres (without special aperture and expensive chemical pre-treatment), we can observe higher improvement of tensile modulus compared to cellulose fibre filled rPP, which has a special bleaching pre-treatment and a higher price. In that perspective the selection of the newsprint fibre reinforcement provides a better economic decision. Moreover, the increase of the tensile strength and morphological characteristics of the composites confirmed good adhesion between the natural fibres and rPP. The addition of fillers significantly limited the chain movements in the polymer system and resulted in higher stiffness and lowered the elongation at break values. It seems that these composites can be processed with classical plastic transformation technologies, like injection moulding or conventional extrusion compounding. The addition of recovered natural fibres to waste plastic matrices thus renders the resulting composites to be viable from both the mechanical properties and the environmental points of view. Besides, these types of materials may be reclaimed and recycled for the production of second-generation composites, when mechanical recycling is applied. Through the mentioned recycling method, the materials can be efficiently re-processed excluding the energy recovery or disposal practices, without changing their chemical structure.

\section{AKNOWLED GEMENTS}

The research leading to these results has received funding from the European LIFE Programme under the sub-program for environment and resource efficiency with the grant agreement $n^{\circ}$ LIFE17 ENV/SI/000119. Special acknowledgement goes also to all project partners: AITIIP, ITB, ECOPULP, ADRIA Mobil and OMAPLAST, and to the Department of Wood Science and Technology (Chair of Wood Pests, Modification and Protection of Wood) from Biotechnical Faculty of University of Ljubljana for their technical assistance in FT-IR measurements.

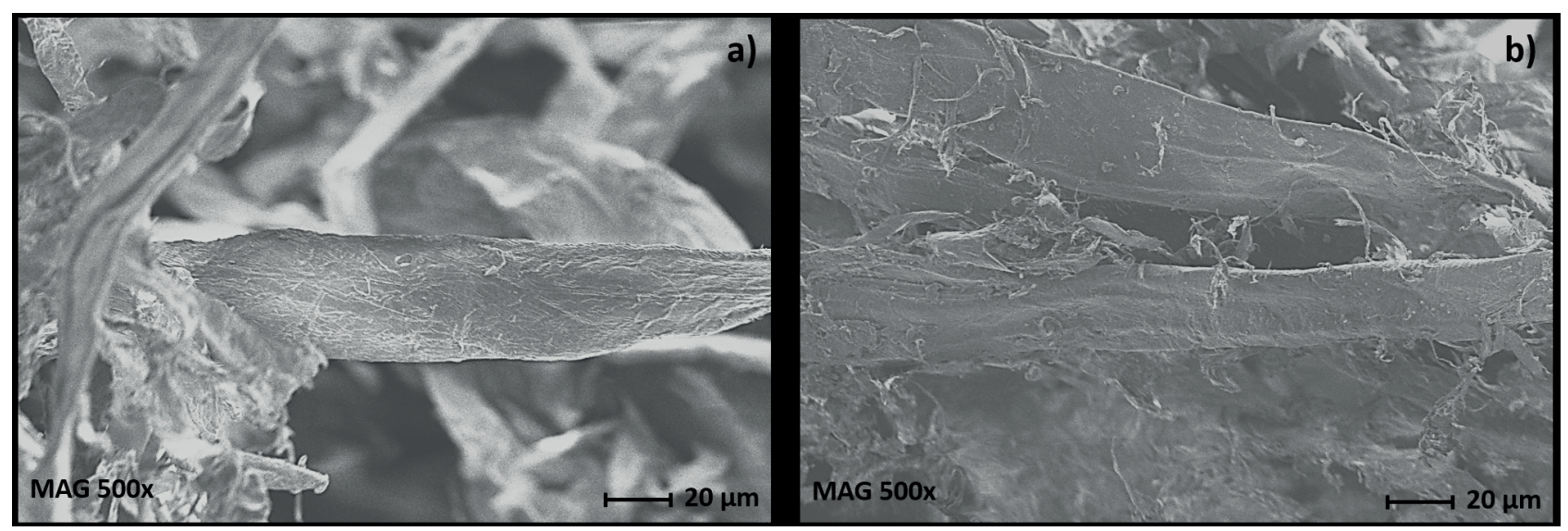

FIGURE 4: SEM micrographs of a) chemically pulped and bleached cellulose fibers, and b) mechanically recycled newsprint fibers. 

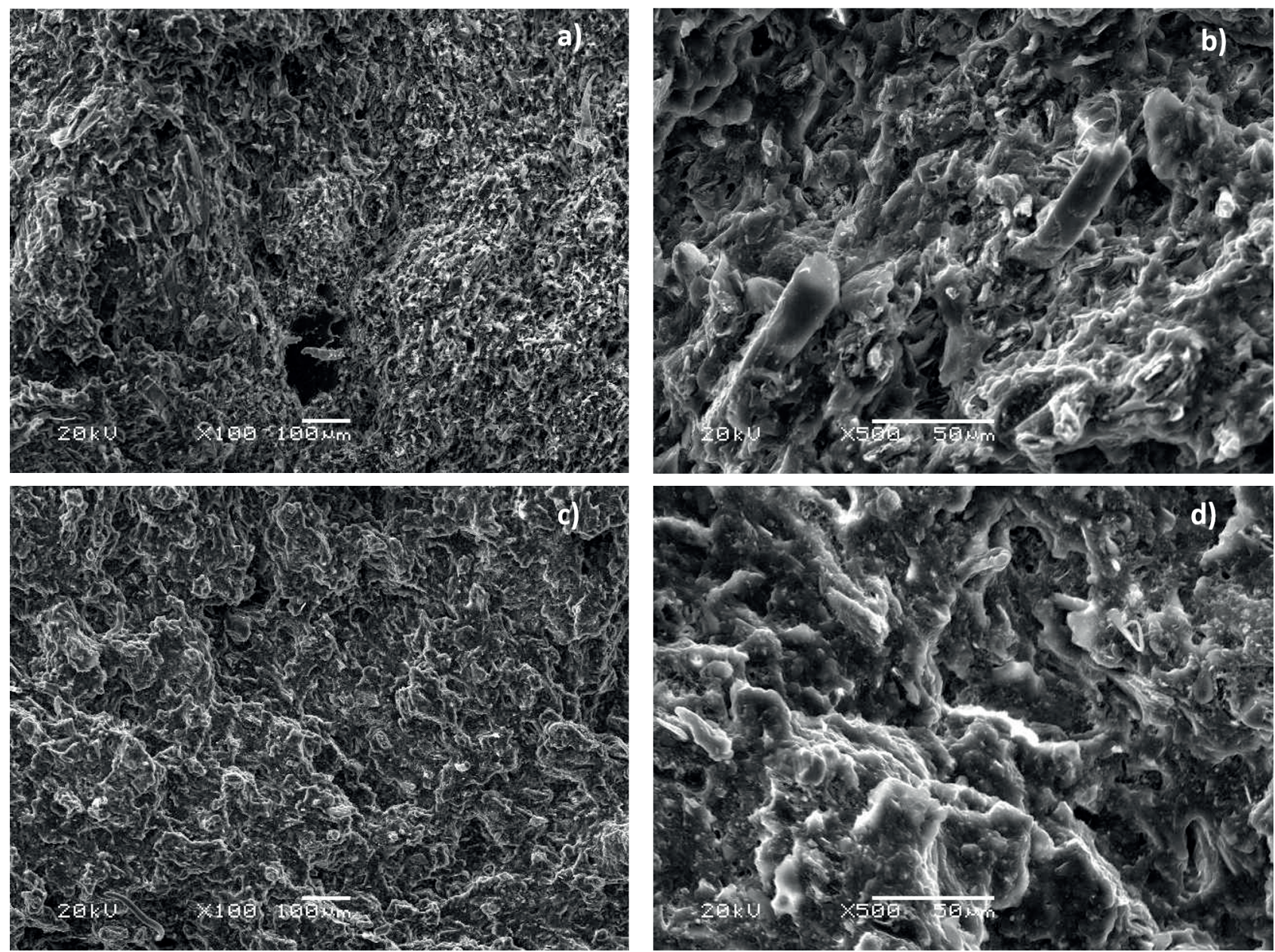

FIGURE 5: Tensile fractured surfaces of a) rPP filled with $40 \mathrm{wt} . \%$ of $\mathrm{CF}, \mathrm{b}$ ) higher magnification of Figure $5 \mathrm{a}, \mathrm{c}$ ) rPP filled with $40 \mathrm{wt}$.\% of $\mathrm{NP}$, and d) higher magnification of Figure 5c.

\section{REFERENCES}

Ashori, A., Nourbakhsh, A. 2008. A comparative study on mechanical properties and water absorption behavior of fiber-reinforced polypropylene composites prepared by OCC fiber and aspen fiber. Polym. Compos., 29:574-78.

Backström, M., Fellers, C., and Htun, M. 1999. The influence of kappa number and surface energy on paper-to-paper friction. Nord. Pulp Pap. Res. J., 14(3): 204-208.

Camacho, W., Karlsson, S. 2001. NIR, DSC, and FTIR as quantitative methods for compositional analysis of blends of polymers obtained from recycled mixed plastic waste. Polym Eng Sci, 41: 16261635.

EC (2015). Communication from the Commission to the European Parliament, the Council, the European Economic and Social Committee and the Committee of the Regions, Closing the loop - An EU action plan for the Circular Economy, COM. 2015, 614 final, Brussels/BE, 2 December 2015

EMF and McKinsey. 2015. Growth within: a circular economy vision for a competitive Europe, Ellen MacArthur Foundation and McKinsey Center for Business and Environment: 126

European Paper Recycling Council (EPRC) monitoring report. 2017. European Declaration on Paper Recycling 2016-2020. Available at http://www.paperforrecycling.eu/publications/

Gregersen, Ø.W., Skinnarland, I., Johnsen, P.O., et al. 1995. Qualitative Methods for the Study of Lignin Distribution in Wood and Surface layers of unbleached Pulp fibers and Paper. J. Pulp Pap. Sci., 21(8): 285-287.

Holbery, J., Houston, D. 2006. Natural-fiber-reinforced polymer composites inautomotive applications. JOM, 58(11):80.
Jariwala, H., Jain, P. 2019. A review on mechanical behavior of natural fiber reinforced polymer composites and its applications. Journal of Reinforced Plastics and Composites, 38 (10): 441-453.

Kalia, S., Kaith, B.S., Kaur, I. 2011. Cellulose Fibers: Bio- and Nano-Polymer Composites, Green Chemistry and Technology. Springer, Heidelberg/Dordrecht/London/New York, 2011.

Kibblewhite R.P. 1983. The fibers of radiata pine mechanical pulps. Appita J., 36(4): 272.

Kowaluk G. 2017. Lignocellulosic Fibers Composites: An Overview, Handbook of Composites from Renewable Materials, 293 308

Kumar, A., Choudhary, V., Khanna, R., Cayumil, R., Ikram-ul-Haq, M., Sahajwalla, V., Kumar, I. Angadi, S., E. Paruthy, G., S. Mukherjee, P., Park, M. 2017. Recycling polymeric waste from electronic and automotive sectors into value added products. Frontiers of Environmental Science \& Engineering, 11(5):4

LIFE17 ENV/SI/000119. Implementation of a new Circular Economy through the valorisation of postconsumer PLAstic waste and reclaimed pulp FIBer. https://ceplafib.eu/

Lin, J.H. Pan, Y.J., Liu, C.F. Huang, C.L., Hsieh, C.T, Chen, C.K., Lin, Z.Y and Lou, C.W. (2015) Preparation and Compatibility Evaluation of Polypropylene/High Density Polyethylene Poly-blends. Materials, 8, 8850-8859.

Lopez-Manchado, M., Biagiotti, J., Torre, L., Kenny, J. 2000. Effects of reinforcing fibers on the crystallization of polypropylene. Polymer Engineering and Science, 40:2194-2204.

Mochane, M.J., Mokhena, T.C., Mokhothu, T.H., et.al. 2019. Recent progress on natural fiber hybrid composites for advanced applications: A review. eXPRESS Polymer Letters, 13 (2), 159-198.

PlasticsEurope. 2018. Plastics - the Facts 2018. PlasticsEurope-Association of Plastic Makers. Available at http://www.plasticsrecyclers.eu/plastic-recycling 
Shen, Li., and Ernst Worrell. 2014. Plastic Recycling. In Handbook of recycling: State-of-the-art for practitioners, analysts, and scientists. Edited by Ernst Worrell and Markus A. Reuter, 179-90. Amsterdam [etc.]: Elsevier.

Sichina, W.J. 2000. Characterization of the quality of recycled polymers using DSC. Perkin Elmer Instruments.

Sydow, Z., Bieńczak, K. 2018. The overview on the use of natural fibers reinforced composites for food packaging. Journal of Natural Fibers, $00(00), 1-12$.
TN 48 Polymer Heats of Fusion. TA Instruments, 23.

Wunderlich, B. 1990. Thermal Analysis, 417-431, Academic Press, USA, 1990.

Yang, H.-S., Kim, H.-J., Park, H.-J., Lee, B.-J., and Hwang, T.-S. 2007. Effect of compatibilizing agents on rice-husk flour reinforced polypropylene composites. Composite Structures, 77(1): 45-55.

Žepič, V., Poljanšek, I., Oven, P., Čop, M. 2016. COST-FP1105: Properties of PLA films reinforced with unmodified and acetylated freeze dried nanofibrillated cellulose. Holzforschung, 70:1125-1134 